\title{
A Five-Dimensional Requirements Elicitation Framework for e-Learning Systems
}

\author{
Hien Minh Thi Tran and Farshid Anvari
}

\begin{abstract}
During organizational changes, a system that often has biggest impact on the changes is a new Accounting Information Systems (AIS). Change management can be facilitated by training the affected employees. E-learning systems and services have been increasingly used to mass train employees about the changes and to empower employees to take a more active role in the creation and dissemination of knowledge. Despite a growing demand for e-learning systems and services, there is a lack of a framework that can guide software engineers and educators to elicit requirements from stakeholders, educators and users of AIS. In this paper we propose a five-dimensional requirements elicitation framework for e-learning systems which use the principles of User-Centered Design, the Knowles' theory of andragogy and the Bloom's Revised Taxonomy in a context of change management. We incorporate the E-USABLE framework (Effectiveness, Utility, Safety, Auditability, feedBack, Learnability and Efficiency) to guide the design of questionnaires for requirements elicitation and evaluation of an e-learning system.
\end{abstract}

Index Terms-e-Learning, requirements elicitation, change management, evaluation, accounting information system.

\section{INTRODUCTION}

In recent years, there is a greater demand for information from Accounting Information Systems (AIS) [1]. The roles and requirements of AIS have broadened significantly to include diverse areas such as "reporting on nonfinancial measures, auditing information systems, implementing management controls within information systems, and providing management consulting services" [2]. Organizational changes involve many parties such as technical teams, business project sponsors, managements as well as end-users of the products or services. Hence dissemination of knowledge is needed for change to be smooth. During organizational change, to empower employees to take a more active role in the creation and dissemination of knowledge, in a context of AIS change management, is a complex process; the process involves diverse groups of stakeholders, subject domain experts, software engineers, technical experts, pedagogical experts, educators, management and staff. E-learning is an emerging solution for dissemination of knowledge to stakeholders and AIS users.

Manuscript received January 17, 2016; revised March 17, 2016. This paper has been supported by Macquarie University's Foundation in Learning and Teaching Alumni Scholarship.

The authors are with Macquarie University, Sydney, Australia (e-mail: hien.tran@mq.edu.au, farshid.anvari@acm.org).
Despite a growing demand for e-learning systems and services, there is a lack of a framework that can guide software engineers and educators to design questionnaires to elicit requirements from stakeholders for e-learning systems in the context of AIS change management. In this paper, we propose a Five Dimensional Requirements Elicitation Framework (5DREF - Change Management, User Characteristics, Knowledge, Cognitive Process and Evaluation) for design of an e-learning system. The 5DREF integrates AIS change management with usability, theory of andragogy, Bloom's Revised Taxonomy and User-Centered Design (UCD). The 5DREF is inspired from different techniques that are adopted from diverse disciplines to guide software engineers and educators to guide the design of questionnaires to elicit requirements from stakeholders and users for e-learning applications in the context of AIS change management.

The rest of the paper is organized as follows. After the background and related work, we discuss the E-USABLE framework [3] used to evaluate applications. We outline the need for and provide the detailed description of the 5DREF, and demonstrate how the 5DREF can assist in designing questionnaires to elicit requirements for e-learning applications in a context of AIS change management.

\section{BACKGROUND AND RELATED WORK}

Requirements elicitation is about understanding the needs of users and project sponsors and to communicate these needs to the system developers [4]. There are many frameworks to elicit requirements for e-learning systems; however these frameworks often focus on one general area of requirements. For example Coughlan et al. [5] proposed a framework which focuses on communication and Zowghi and Jin [6] proposed a framework which focuses on aligning with enterprise business goals; eliciting requirements involves intense communication between users and designers which was addressed by Coughlan et al. [5] with a framework to identify issues with communications and to assist stakeholders to effectively communicate their requirements; to elicit requirements for IT services, attention to the enterprise strategies and the interactive environment are essential [6].

Grabski et al. [2] reviewed major accounting-related themes across Enterprise Resource Planning topics and noted that "change management practice has long incorporated the need for education because it addresses both knowledge acquisition and behavioral change" (p. 10). Knowledge acquisition that leads to behavioral changes requires continuous professional development and real-time learning 
[7]. In order to embrace change, affected employees need to be trained about new processes and activities. In recent years computing equipment has changed the way users learn, with the resultant increase in demand for e-learning applications. In the past decades, significantly increasing number of e-learning systems and services have been employed to train employees [8].

Users of an e-learning application can be diverse and numerous. Therefore software engineers and educators must examine issues from multiple perspectives and be open to new insights. UCD methodology considers the goals of the users as a primary requirement. The main usability goal in e-learning systems is that it should be easy for users to operate the e-learning application so that they can concentrate on learning new materials, and this can be better achieved if designers take into account users' expertise [9]. De Marsico, et al. [9] have highlighted the role of multiple members in the lifecycle design team of domain, pedagogical and technical experts, students and teachers as well as individuals with disabilities to address accessibility issues for e-learning applications.

In the context of AIS change management, users are adults. Knowles defined characteristics of adult learners as [10]:

1) Adults are self-directed learners.

2) Adults bring a variety of life experiences that need to be valued and used in the learning process.

3) Adults are ready to learn when they perceive a need to know.

4) Adults want to apply what they have learned as quickly as possible. Learning needs to be problem-focused or task-centered. Learning activities need to be clearly relevant to their needs.

5) Adults are motivated to learn because of internal factors such as a better quality of life, recognition, self-confidence, self-esteem etc.

Users of AIS include finance officers, accountants, auditors, administrative assistants, faculty general managers, technical assistants, managers, human resources officers, researchers, postgraduate students, heads of departments, personal assistants to executives and deans [11]. Consequently, each group of users has their own specified learning objectives. For design of e-learning systems or services, software engineers elicit requirements from users of the application, educators and experts, such as domain, technical and pedagogical experts.

\section{THE E-USABLE FOR EVALUATION}

Empirical studies have found that usability is one of the top three most important quality requirements [12], [13]. The international standard ISO 9241 defines usability as "the extent to which a product can be used by specified users to achieve specified goals with effectiveness, efficiency and satisfaction in a specified context of use".

To effectively and efficiently address user requirements, e-learning applications must have tools for educators to convey various levels of knowledge and cognitive processes so that learners of AIS can recognize and solve problems. Bloom's Revised Taxonomy incorporates the Knowledge and the Cognitive Process Dimensions. The Knowledge Dimension, which refers to contents of learning, consists of Factual, Conceptual, Procedural and Meta-cognitive knowledge. The Cognitive Process Dimension, which refers to learning processes, is grouped into six categories: Remember, Understand, Apply, Analyze, Evaluate and Create [14]. Accordingly, to satisfy learning needs of different user groups which have specified goals at different levels of cognitive processes, different tools are required.

There are many usability criteria to evaluate a website application such as the Ten Heuristics constructed by Nielsen and Molich [15] and the Eight Golden Rules constructed by Shneiderman [16]. However, the focus of these usability criteria are on the user interfaces. They do not address the diverse AIS users' specified learning objectives. Cronholm et al. [17] found that there is a need for usability criteria on the communication and business process level as the users of computing system wish to achieve higher goals than just interact with the system.

In the AIS change management context, designing e-learning applications to meet users' needs, at the business process level, can be very complex. To assist managers to work through the complexity of leading and managing the changing technological landscape of AIS, Tran and Anvari [18] have proposed the 9-C Model which consists of nine interrelated factors: Capacity building, Champions of change, Collaboration, Communication, Coherence-making, Communities, Culture for learning and evaluation, Curriculum development and Continuous improvement. By adapting Nielsen and Molich [15] ten heuristics, synthesizing the literature and reviewing case studies and, based on years of experience in developing and testing applications, Anvari and Tran [3] developed the E-USABLE framework to meet objectives at the business process level and quality requirements. The E-USABLE framework has seven categories: Effective to use (effectiveness); have good Utility (utility); Safe to use/prevent possible errors; the data entries are Auditable (auditability); the application provides good feedBack (feedback); the application is easy to Learn (learnability) and Efficient to use (efficiency). The feedback category is used to evaluate whether the application has tools that promote user confidence and an expectation of success. Scaffolds and prompt feedback are essential for success in e-learning. Quizzes, in an e-learning application provide immediate feedback to the participant. It can also be used to assess participants' ongoing performance. For deep learning, the application provides a discussion forum for participants to post their views, ask questions from, and provide answers to each other. High quality e-learning for professionals requires social interaction and collaboration with peers and connecting new knowledge to past experiences [19]. Participants can enhance their learning abilities by actively interacting with technology and real-world applications [20].

The three of the top five most important quality requirements are performance, reliability and flexibility [13]. The two categories of the E-USABLE framework, effectiveness and efficiency, evaluate the performance requirement. The safety and audit-ability categories evaluate the reliability requirement. The utility, feedback and learnability categories evaluate the flexibility requirement. 


\section{ThE FIVE-DimENSIONAL REQUIREMENTS ELICITATION FRAMEWORK IN CONTEXT OF AIS}

Drawing on the Knowles' theory of andragogy [10], the Knowledge Dimension and the Cognitive Process Dimension [14], the 9-C Model of Change Management [18], the E-USABLE framework [13] and our experiences, we propose the Five-Dimensional Requirements Elicitation Framework (5DREF). The 5DREF consists of five dimensions: Change Management, User Characteristics, Knowledge, Cognitive Process and Evaluation. The 5DREF which starts from the 'why' then follows by the 'who', the 'what' and the 'how' and ends with the evaluation of the knowledge gained.

Change Management Dimension: This dimension which answers the 'why' the change is necessary, elicits requirements from stakeholders, project sponsors and project owners about business requirements in a context of AIS change management. As part of the 5DREF for AIS e-learning applications we use the 9-C Model of Change Management that consists of nine interrelated factors [18]:

1) Capacity building: Capacity building builds users knowledge and skills to embrace change.

2) Champions of change: Champions of change are people who actively promote the innovation, build support, overcome resistance and ensure that the innovation is implemented [21].

3) Collaboration: Different stakeholder groups are represented and work together to collectively conduct the process of requirements elicitation [6].

4) Communication: Communication during implementation is far more important than communication prior to implementation because communication in the abstract, in the absence of action, means almost nothing [22].

5) Coherence-making: Coherence-making facilitates employees' understanding of new processes and the meaning they make out of the change.

6) Communities: Communities facilitate learning from peers [23].

7) Culture for learning and evaluation: Culture for learning and evaluation encourage participants through interaction with each other to become committed to self-improvements; it is evaluated through reflection and peer feedback.

8) Curriculum development: Learning contents provide for the Knowledge and Cognitive Processes to meet the objectives at the business process level and increase collective capacity. Constructivism's perspectives on the active role of the learner have had great impact on instructional design [24] which in turn has great influence on requirements elicitation.

9) Continuous improvement: Continuous improvement helps people to understand changes in processes [23].

User Characteristics Dimension: This dimension which answers the 'who' are involved in change, recognizes the characteristics of operational staff, management and other users of the application who are adults. Hence the framework includes the theory of andragogy that requires learning needs to be relevant, problem-focused or task-centered.

Knowledge Dimension: The Knowledge Dimension which answers the 'what' to change, consists of Factual, Conceptual,
Procedural and Meta-cognitive knowledge [14]. In this dimension information from and knowledge of domain experts and specialists are utilized. Domain experts exhibit high level of knowledge in regards to subject matters. Requirements elicitation techniques such as interviewing and questionnaire based surveys can be used to obtain domain experts' requirements. Quality of the content plays a significant factor for effectiveness of e-learning applications.

Cognitive Process Dimension: The Cognitive Process Dimension, which answers the 'how' to change, refers to learning processes. It is grouped into six categories according to Bloom's taxonomy: Remember, Understand, Apply, Analyze, Evaluate and Create; with Remember being the least complex and Create being the highest rung of the Cognitive Process [14]. In this dimension educators and pedagogical experts provide information in accordance with the needs of the users and by taking into account participants' cognitive process dimension, educators can design course materials that match learners' cognitive processes [3].

Evaluation Dimension: Evaluation helps leaders to monitor the implementation processes, to gauge their success and, to identify and resolve issues in a timely fashion. This dimension elicits requirements from all parties, such as: stakeholders, users, domain experts and educators. The 9-C factors and the E-USABLE can provide a framework to evaluate the quality of e-learning applications.

\section{THE APPLICATION OF THE 5DREF IN DEVELOPING AIS E-LEARNING COURSE APPLICATIONS}

At a research-intensive Australian University, the lead author has been responsible for designing AIS courses for professional staff since 2007 in a face-to-face arrangement. It has been found that AIS users' requirements are varied as they work in various departments and have different duties and responsibilities. The University is dynamic and hence changes are common. The number of users of AIS has increased due to both users' increased vigilance over budget, an increased number of existing employees engaged in new roles or new employees are recruited. The face-to-face training workshops do not adequately cover the needs of the users as their prior knowledge and duties are different. Often the waiting time for scheduled face-to-face training workshops are long as many who start in their new roles need training to be effective in their duties. Senior professionals and academics cannot devote a set period of time to participate in face-to-face training workshops. E-learning AIS courses can improve the situation by offering supplementary in-class activities, empowering educators to reinforce course materials and participants to engage with the materials [25].

Table I summarizes guidelines to design questionnaires for requirements elicitation, and for evaluating an e-learning application using the Knowles' theory of andragogy and the E-USABLE framework. In this section we illustrate with examples how the framework is intended to be used to develop questionnaires to prompt stakeholders, project sponsors, champions of change, key users, and educators to elicit requirements for the design of an application for e-learning courses. 
Change Management Dimension: This dimension which answers 'why' to change, uses the 9-C Model of Change Management [18] to solicit requirements from management and employees about the need, appropriateness and use of tools such as announcement boards, wikis and blogs to communicate purposes of change (Communication), allow learners to collaborate (Collaboration) and management to encourage employees to become learners and participate in discussions (Champion of change). Though postings of views from various parties will assist employees (as guests users of the application) and learners to make sense of the organizational changes, management and employees should also have awareness that all activities in using these tools have to be balanced with maintenance of confidentiality of the strategic rationale - the risk of competitors taking advantage or subjecting views to critical scrutiny (Coherence making and Capacity building). While soliciting requirements, the functionality of tools are investigated to ensure that the tools meet customization requirements that regulates access and use of the tools by relevant sections of the community (Communities). For example, the policies and procedures employed to set and check the credential of the users of the tools, permission for employees to take part as guest, the activities that guest can perform (e.g., guests may be allowed to read parts of the contents and may not be allowed to post), or provision made available for learners to anonymously post questions. In this dimension, the requirements for monitoring learners' activities are also investigated. The monitoring facilities provide feedbacks, conduct surveys and investigate $\log$ files. The information helps to detect needs for incorporating new requirements within the application (Culture for learning and evaluation) and provide timely feedback to the learners. The self-improvement measures can be items such as online quizzes, hands-on real-life exercises and selection of learning styles e.g. audios, texts or videos (Curriculum development), graphs to show progress and functions to align learning materials with organizational goals (Continuous improvement).

User Characteristics Dimension: In large organization such as universities, the users of the AIS e-learning application are diverse. In designing the content of the e-learn application, learners' requirements such as learners' personalities which affect their learning, their prior knowledge and availabilities are taken into account. E-learning application should have tools for educators to implement online expectation forms which include open-ended questions or free text entries about participants' needs and views. This information helps educators to plan for and to provide tools to suit various learners' learning preferences. To meet the adult learner characteristics the course material allows for self-directed learners to learn what they need and when they need, with the course material being relevant to the learners occupation and hence allows them to apply what they have learnt as quickly as possible. The range of course content motivates the learners to learn. Table I summarizes the above list.

Knowledge Dimension: In this dimension, requirements for the content of the e-learning application are solicited from domain experts. It is ensured that the application has various tools to support staff development activities at different levels of knowledge: the existing knowledge and the target level of knowledge to be gained at the conclusion of sessions with the e-learning application. For example, the AIS e-learning application has tools for domain experts to convey factual knowledge which is static information, to demonstrate conceptual knowledge via videos and graphs which can vary according to contents. To teach procedural knowledge, the application has to have more sophisticated tools such as interactive tools. For domain experts to encourage meta-cognitive knowledge the e-learning application provides reflective tools. Appropriate tools are provided for the learners' who are reflective practitioners, to improve their professional skills based on their on-going reflection with respect to their performance during and after accomplishing sessions within e-learning application [26].

Cognitive Process Dimension: This dimension solicits requirements from pedagogical experts and educators. Requirements are solicited for e-learning applications for required tools to enable facilitators and/or educators load various learning contents in various formats and to scaffold learners. The need for tools to teach factual and conceptual knowledge is investigated. For example requirements for tools to facilitate direct instructional approach in which the educators break a new body of knowledge into small steps with clear objectives to provide learners with opportunity to practice with feedback in each step learnt [27] or requirements for tools to integrate real-life worked-example scenarios into teaching is investigated. Hence the e-learning application encourages participants to learn at the higher rung of the cognitive process dimension [28]. Depending on capability of the users, educators require the format and order of presentation of the learning materials be varied and features be incorporated so that the schema generation that occurs with any new learning is within learners' working memories [29] however "learners may need to be presented with the materials in their full complexity only in a later learning phase" [30]. Hence different levels of cognitive processes, require different functional tools. Some examples for the AIS e-learning application are: (1) simple webpages are available for users of application to remember factual knowledge; (2) simple online forms are available for subject domain experts to enter glossary terms into the application or directly upload materials to the application; (3) tools for educators to load materials onto the application and for users to easily retrieve information about the lessons learnt.

Evaluation Dimension: learners, domain experts, educators and other stakeholders evaluate the e-learning application from their own perspective [3]. Some of the criteria used to evaluate the AIS e-learning application are: (1) participants confidently use the AIS application after attending e-learning courses (capacity building); (2) tools are available within e-learning application for learners to work collaboratively (collaboration); (3) communities surrounding discussion forums within e-learning application grow and the learners are assisting each other (communities); (4) management encourage new staff to participate in the forums (culture for learning and evaluation); (5) the e-learning application can assists educators to effectively convey the business processes to the users (Effectiveness); (6) the e-learning application has tools that assist users to measure 
their achievement in respect to the business goals (Utility); (7) the application is safe to use as it prevents possible errors (safety); (8) data entries can be audited (audit-ability); (9) User Interfaces provide feedback (feedBack); (10) it is easy to learn to operate the e-learning application (learn-ability); (12) the application is efficient to use (efficiency); (13) content presentation can be adapted according to the learners' needs (e.g., managers have different needs compared with researchers); (14) Learners can use the AIS e-learning application at the time that they are ready to learn (e.g. access is unrestricted and busy executives can spend small amounts of time at each session). (15) The AIS e-learning application provides learners with prompt feedback from the preloaded Questions and Answers bank so that learners can self-direct their learning. The application has activities which allow learners to self-regulate their learning effectively.

TABLE I: SAMPLE OF REQUIREMENTS OF AN E-LEARNING COURSE APPLICATION

\begin{tabular}{|c|c|c|c|c|c|c|c|}
\hline \multirow{2}{*}{$\begin{array}{l}\text { KNOWLES' } \\
\text { THEORY OF } \\
\text { ANDRAGOGY }\end{array}$} & \multicolumn{7}{|c|}{ USABILITY DIMENSION } \\
\hline & EFFECTIVENESS & UTILITY & SAFETY & AUDITABILITY & FEEDBACK & $L E A R N-A B I L I T Y$ & EFFICIENCY \\
\hline $\begin{array}{l}\text { ADULTS } \\
\text { SELF-DIRECT } \\
\text { THEIR } \\
\text { LEARNING }\end{array}$ & \multicolumn{2}{|c|}{$\begin{array}{l}\text { AIS e-learning application provides the } \\
\text { following tools/resources that } \\
\text { effectively assist users to self-direct } \\
\text { their learning: } \\
\text { - Reading materials } \\
\text { - Interactive exercises on AIS } \\
\text { - Quiz questions } \\
\text { - Videos } \\
\text { - Blogs } \\
\text { - Discussion Board } \\
\text { - Quiz feedback } \\
\text { - Facilitator's feedback } \\
\text { - Peers' feedback } \\
\text { (System Quality \& System Usability) }\end{array}$} & $\begin{array}{l}\text { Users can safely } \\
\text { self-direct their } \\
\text { learning. (e.g. the } \\
\text { users are able to } \\
\text { learn skipped } \\
\text { material, refresh } \\
\text { and repeat } \\
\text { exercises) } \\
\text { (System Usability) }\end{array}$ & $\begin{array}{l}\text { AIS e-learning } \\
\text { application } \\
\text { provides users } \\
\text { with tools to audit } \\
\text { their learning } \\
\text { processes } \\
\text { (System Quality) }\end{array}$ & $\begin{array}{l}\text { AIS e-learning } \\
\text { application } \\
\text { provides users } \\
\text { with feedback that } \\
\text { they can self-direct } \\
\text { their learning e.g. } \\
\text { users receive } \\
\text { feedback from the } \\
\text { pre-loaded } \\
\text { Questions and } \\
\text { Answers bank. } \\
\text { (System Usability } \\
\text { Content Quality) }\end{array}$ & \begin{tabular}{|l} 
AIS e-learning \\
application has \\
materials that are \\
learnable by users \\
of diverse \\
background (e.g. \\
users can select \\
their learning \\
preferences such \\
as. audio, texts, \\
videos). \\
(System Usability \\
Content Quality)
\end{tabular} & $\begin{array}{l}\text { AIS e-learning } \\
\text { application has } \\
\text { tools which users } \\
\text { can efficiently } \\
\text { use the system } \\
\text { (e.g. distance } \\
\text { learning over } \\
\text { weak connections, } \\
\text { very small page } \\
\text { load time, } \\
\text { capacity for large } \\
\text { number of } \\
\text { participants). } \\
\text { (System Quality) }\end{array}$ \\
\hline $\begin{array}{l}\text { ADULTS } \\
\text { LEARN WHEN } \\
\text { USERS ARE } \\
\text { READY }\end{array}$ & $\begin{array}{l}\text { Users can learn } \\
\text { from the } \\
\text { application when } \\
\text { they are ready to } \\
\text { learn (e.g. access is } \\
\text { unrestricted and } \\
\text { busy executives can } \\
\text { spend small } \\
\text { amounts of time at } \\
\text { each session). } \\
\text { (System Quality) }\end{array}$ & $\begin{array}{l}\text { The application } \\
\text { has utilities for } \\
\text { new users to } \\
\text { enroll anytime of } \\
\text { the year. } \\
\text { (System Usability) }\end{array}$ & $\begin{array}{l}\text { The application } \\
\text { demonstrates to } \\
\text { new users that the } \\
\text { application is } \\
\text { secure } \\
\text { (System Quality). }\end{array}$ & $\begin{array}{l}\text { The application } \\
\text { has tools for new } \\
\text { users to audit } \\
\text { their progress } \\
\text { when needed. } \\
\text { (System Quality) }\end{array}$ & \begin{tabular}{|l|} 
The application \\
provides new \\
users with \\
feedback to \\
scaffold their \\
learning. \\
(System Usability)
\end{tabular} & \begin{tabular}{|l|} 
The application \\
has self-help \\
materials that \\
assist new users in \\
their learning. \\
(Content Quality)
\end{tabular} & $\begin{array}{l}\text { The application is } \\
\text { efficient to use } \\
\text { (e.g. the start time } \\
\text { is short even when } \\
\text { the link is slow). } \\
\text { (System Quality) }\end{array}$ \\
\hline $\begin{array}{l}\text { ADULTS } \\
\text { APPLY WHAT } \\
\text { USERS HAVE } \\
\text { LEARNED AS } \\
\text { QUICKLYAS } \\
\text { POSSIBLE }\end{array}$ & $\begin{array}{l}\text { The application } \\
\text { provides } \\
\text { worked-examples } \\
\text { and activities which } \\
\text { users can } \\
\text { effectively apply. } \\
\text { (System Usability } \\
\text { Content Quality) }\end{array}$ & $\begin{array}{l}\text { The application } \\
\text { has utilities for } \\
\text { educators to load } \\
\text { practical examples } \\
\text { for all learners. } \\
\text { (System Usability } \\
\text { System Quality) }\end{array}$ & \begin{tabular}{|l|} 
AIS e-learning \\
application has \\
activities that \\
users can safely \\
apply. \\
(Content Quality)
\end{tabular} & \begin{tabular}{|l|} 
AIS e-learning \\
application has \\
tools that assist \\
users to audit \\
their knowledge of \\
AIS (e.g. the \\
application \\
provides a recap \\
and the last steps). \\
(System Usability)
\end{tabular} & \begin{tabular}{|l|} 
The application \\
has facilities for \\
educators to \\
provide feedback \\
to scaffold users \\
of diverse \\
background. \\
(System Usability \\
Content Quality)
\end{tabular} & $\begin{array}{l}\text { The application } \\
\text { has customized } \\
\text { learning materials } \\
\text { that all users can } \\
\text { learn and apply to } \\
\text { their positions. } \\
\text { (System Usability } \\
\text { Content Quality) }\end{array}$ & $\begin{array}{l}\text { The application } \\
\text { has worked } \\
\text { examples that } \\
\text { users can quickly } \\
\text { apply. } \\
\text { (System Usability } \\
\text { Content Quality) }\end{array}$ \\
\hline $\begin{array}{l}\text { ADULTS } \\
\text { BUILD SELF- } \\
\text { CONFIDENCE }\end{array}$ & $\begin{array}{l}\text { The application has } \\
\text { activities which } \\
\text { users can } \\
\text { self-regulate their } \\
\text { learning } \\
\text { effectively. } \\
\text { (System Usability } \\
\text { Content Quality) }\end{array}$ & \begin{tabular}{|l|} 
The application \\
has utilities to \\
align learning \\
materials with \\
organizational \\
goals to build \\
users' confidence. \\
(System Usability \\
Content Quality)
\end{tabular} & $\begin{array}{l}\text { The application is } \\
\text { safe for users to } \\
\text { build confidence } \\
\text { (e.g. various } \\
\text { activities are used } \\
\text { to scaffold users } \\
\text { from various } \\
\text { backgrounds). } \\
\text { (System Quality } \\
\text { Content Quality) }\end{array}$ & $\begin{array}{l}\text { The application } \\
\text { has tools that } \\
\text { audit users' } \\
\text { improvement to } \\
\text { build their } \\
\text { confidence e.g. } \\
\text { graphs to show } \\
\text { progress and } \\
\text { improvements. } \\
(\text { System Usability) }\end{array}$ & $\begin{array}{l}\text { The application } \\
\text { provides feedback } \\
\text { that build users' } \\
\text { confidence. } \\
\text { (System Usability } \\
\text { Content Quality) }\end{array}$ & $\begin{array}{l}\text { The application } \\
\text { has tools for } \\
\text { educators to design } \\
\text { learning materials } \\
\text { that can build } \\
\text { users' self- } \\
\text { confidence in their } \\
\text { abilities to learn } \\
\text { AIS. } \\
\text { (System Usability } \\
\text { Content Quality) }\end{array}$ & $\begin{array}{l}\text { The application } \\
\text { has activities that } \\
\text { assist users to } \\
\text { efficiently gain } \\
\text { confidence in } \\
\text { their knowledge } \\
\text { of AIS. } \\
\text { (System Usability } \\
\text { Content Quality) }\end{array}$ \\
\hline
\end{tabular}


Evaluation of performance, reliability and flexibility requirements [13], the three of the top five most important quality requirements are mapped to the categories listed above: performance requirements are covered by the effectiveness and efficiency categories of the E-USABLE framework; reliability requirements are covered safety and audit-ability categories of the E-USABLE framework; flexibility requirements are cover by the utility, feedback and learnability categories of the E-USABLE framework.

\section{CONCLUSION}

In this paper, we have proposed the Five-Dimensional Requirements Elicitation Framework (5DREF) for eliciting e-learning system requirements that stems from integrating User-Centered Design, teaching and learning theory and, change management. The framework consists of five dimensions: Change Management, User Characteristics, Knowledge, Cognitive Process and Evaluation. The framework, clarifies why, who, what, how and evaluation of the knowledge gained. We have discussed how the 5DREF can assist software engineers to author questionnaires to solicit requirements for the design and development of an application for the AIS e-learning course. The novel contribution of the 5DREF is that it provides a multi-dimensional framework that integrates the work of multiple-disciplines to assist both software engineers and educators to examine requirements from multiple perspectives of diverse groups of users of the e-learning systems such as subject domain experts, software engineers, technical experts, pedagogical experts, educators, stakeholders, management and staff who are e-learning users. To the best of our knowledge, there is no framework for software engineers and educators to address the requirements of diverse groups of users of AIS e-learning applications from multiple disciplines such as computing, accounting, education, organizational learning and change management. We plan to conduct empirical study to evaluate the effectiveness of the proposed framework through action research.

\section{ACKNOWLEDGMENT}

We thank Mr. Paul Vincent for his valued comments and Dr. Marina Harvey for her encouragement.

\section{REFERENCES}

[1] F. Belfo and A. Trigo, "Accounting information systems: Tradition and future directions," Procedia Technology, vol. 9, pp. 536-546, 2013.

[2] S. V. Grabski, S. A. Leech, and P. J. Schmidt, "A review of ERP research: A future agenda for accounting information systems," Journal of Information Systems, vol. 25, pp. 37-78, 2011.

[3] F. Anvari and H. M. T. Tran, "Persona ontology for user centred design professionals," in Proc. the ICIME 4th International Conference on Information Management and Evaluation, Ho Chi Minh City, Vietnam, 2013, pp. 35-44.

[4] D. Zowghi and C. Coulin, "Requirements elicitation: A survey of techniques, approaches, and tools," Engineering and Managing Software Requirements, Springer, 2005, pp. 19-46.

[5] J. Coughlan, M. Lycett, and R. D. Macredie, "Communication issues in requirements elicitation: A content analysis of stakeholder experiences," Information and Software Technology, vol. 45, pp. $525-537,2003$
[6] D. Zowghi and Z. Jin, "A framework for the elicitation and analysis of information technology service requirements and their alignment with enterprise business goals," in Proc. 2010 IEEE 34th Annual Computer Software and Applications Conference Workshops, 2010, pp. 269-272.

[7] S. Balzert, P. Fettke, and P. Loos, "A framework for reflective business process management," in Proc. 2012 45th Hawaii International Conference on System Science, 2012, pp. 3642-3651.

[8] J.-M. Batalla-Busquets and C. Pacheco-Bernal, "On-the-job e-learning: Workers' attitudes and perceptions," The International Review of Research in Open and Distributed Learning, vol. 14, pp. 40-64, 2013.

[9] M. De Marsico, S. Kimani, V. Mirabella, K. L. Norman, and T. Catarci, "A proposal toward the development of accessible e-learning content by human involvement," Universal Access in the Information Society, vol. 5, pp. 150-169, 2006.

[10] M. S. Knowles, E. F. Holton III, and R. A. Swanson, The Adult Learner, Routledge, 2012.

[11] H. M. T. Tran and F. Anvari, "The five-dimensional reflective cycle framework for designing financial information management systems courses," Electronic Journal of Information Systems Evaluation, vol. 16, pp. 242-255, 2013

[12] D. Ameller, C. Ayala, J. Cabot, and X. Franch, "How do software architects consider non-functional requirements: An exploratory study," in Proc. 2012 20th IEEE International Requirements Engineering Conference, 2012, pp. 41-50.

[13] J. L. de la Vara, K. Wnuk, R. Berntsson-Svensson, J. Sánchez, and B Regnell, "An empirical study on the importance of quality requirements in industry," SEKE, pp. 438-443, 2011.

[14] L. W. Anderson and D. R. Krathwohl, A Taxonomy for Learning, Teaching, and Assessing: A Revision of Bloom's Taxonomy of Educational Objectives (Abridged Edition), New York: Longman, 2001.

[15] J. Nielsen and R. Molich, "Heuristic evaluation of user interfaces," in Proc. the SIGCHI Conference on Human Factors in Computing Systems, 1990, pp. 249-256.

[16] B. Shneiderman, Designing the User Interface: Strategies for Effective Human-Computer Interaction, MA: Addison-Wesley Reading, 1992, vol. 2.

[17] S. Cronholm, V. Bruno, S. Newell, E. Whitley, N. Pouloudi, J. Wareham et al., "Usability of IT-systems is more than interaction quality-the need of communication and business process criteria," in Proc. 17th European Conference on Information Systems, 2009, p. 1.

[18] H. M. T. Tran and F. Anvari, "Reflective frameworks for change management," in Proc. 8th European Conference on IS Management and Evaluation: ECIME, Ghent, Belgium, 2014, pp. 253-261.

[19] K. Cercone, "Characteristics of adult learners with implications for online learning design," AACE, vol. 16, pp. 137-159, 2008.

[20] J. Ragan, M. Gantner, P. Caffrey, and M. Schultz, "A teaching case using cost/benefit relationships within an ERP system," Journal of Business Case Studies, vol. 2, pp. 17-24, 2011.

[21] J. M. Howell and C. A. Higgins, "Champions of change: Identifying, understanding, and supporting champions of technological innovations," Organizational Dynamics, vol. 19, pp. 40-55, 1990.

[22] M. Fullan, Motion Leadership: The Skinny on Becoming Change Savvy, Corwin Press, 2009.

[23] M. Fullan, C. Cuttress, and A. Kilcher, "Eight forces for leaders of change," Journal of Staff Development, vol. 26, p. 54, 2005.

[24] M. G. Jones and L. Brader-Araje, "The impact of constructivism on education: Language, discourse, and meaning," American Communication Journal, vol. 5, pp. 1-10, 2002.

[25] B. White and J. A. Larusson, "Strategic directives for learning management system planning," Educause, ECAR Research Bulletin, 2010.

[26] D. A. Schön, The Reflective Practitioner: How Professionals Think in Action, 1983, vol. 5126.

[27] S. G. Magliaro, B. B. Lockee, and J. K. Burton, "Direct instruction revisited: A key model for instructional technology," Educational Technology Research and Development, vol. 53, pp. 41-55, 2005.

[28] P. J. DeLotell, L. A. Millam, and M. M. Reinhardt, "The Use of deep learning strategies in online business courses to impact student retention," American Journal of Business Education, vol. 3, 2011.

[29] J. Sweller, J. J. Van Merrienboer, and F. G. Paas, "Cognitive architecture and instructional design," Educational Psychology Review, vol. 10, pp. 251-296, 1998.

[30] J. J. Van Merrienboer and J. Sweller, "Cognitive load theory and complex learning: Recent developments and future directions," Educational Psychology Review, vol. 17, pp. 147-177, 2005. 


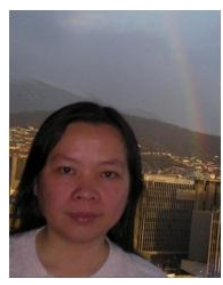

Hien Minh Thi Tran holds a postgraduate certificate in higher education, Macquarie University, 2013, a master of arts degree, from Swinburne University of Technology, 2006, a graduate diploma in management, from University of Southern Queensland, in 2002, a master of commerce, from University of Southern Queensland, 1998, a graduate conversion course in accounting, from University of Tasmania, in 1997, a master degree of engineering science, from University of Tasmania, 1990, and a bachelor degree of engineering with honours, from University of Tasmania, in 1987.

She is currently working at Macquarie University, Sydney, Australia as a systems accountant and a casual academic. She has over 27 years of work experience in software engineering and accounting information systems. She has taught professional staff and students in various topics in engineering, accounting, software developments and mathematics. Her research interests include education, accounting systems and software developments.

Mrs. Tran is a qualified member of the Australian Society of Certified Practising Accountants (CPA). She is featured in Who's Who in Tasmania 2008, Inaugural Print Edition by Crown Content, the century-old publisher of Who's Who.
Farshid Anvari holds a graduate diploma of information technology, from University of Southern Queensland, 1998, a graduate diploma of science, University of Tasmania, 1996, and a bachelor degree of engineering, Swinburne University of Technology, 1984.

He is currently studying for a master of philosophy (MPhil) degree at Macquarie University, Sydney, Australia. He has over 15 years of experience in software engineering. He was working at Australian Biosecurity Intelligence Network (ABIN) CSIRO, University of New South Wales (UNSW) and Special Broadcasting Service (SBS). At ABIN, he developed an application for scientists to disseminate tools. At UNSW, he architected solutions and led the development team for implementation of Healthy Me, an online research platform to support consumer health decision making. At SBS, he designed and implemented the automated digital channel system, SBS Essential, which was highly commended in the Commonwealth Broadcasting Association awards for cost-effective engineering. He also has over 12 years of experience in power engineering, specializing in hydro system modelling and reliability studies. His research interests include cognitive load, user centered design, persona ontology and architecting systems that are economical, robust and reliable.

Mr. Anvari is a member of the Australian Computer Society (ACS) and the Association for Computing Machinery (ACM). 